\title{
(In)eficácia do Princípio de Precaução no Brasil
}

\author{
FERNANDA VIEGAS REICHARDT I \\ - MAYARA REGINA ARAÚJO DOS SANTOS ${ }^{I I}$
}

\section{Introdução}

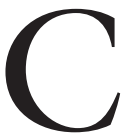

OM O OBJETIVo de revisar o Princípio de Precaução no ordenamento nacional ante os acordos internacionais assumidos pelo Brasil, optamos, nesta fase introdutória, por uma abordagem constitucional. Isso porque o Direito Constitucional Ambiental é o ponto de partida dos deveres, obrigações e responsabilidades referentes à proteção ambiental (Canotilho; Leite, 2012). Ou, como afirma Machado (2004), constitui seu alicerce/fundamento, orientando a geração do direito ambiental e sua implementação.

A Constituição da República Federativa do Brasil de 1988, pelo artigo $225,{ }^{1}$ apresenta o ambiente ecologicamente equilibrado como um direito fundamental de titularidade transinduvidual, isto é, que transcende a esfera pessoal de cada cidadão (Brasil, 1988). A despeito da localização fora do "Título II - Dos Direitos e Garantias Fundamentais” da Constituição, o ambiente ecologicamente equilibrado pertence a essa categoria jurídica conforme doutrina majoritária e jurisprudência. É um direito fundamental de terceira dimensão (Brasil, 1988). A expressão "direitos fundamentais" se aplica àqueles direitos do ser humano reconhecidos na esfera constitucional de determinado Estado, ao passo que a expressão "direitos humanos" guarda relação com os documentos de direito internacional (Sarlet, 2010). Podemos defini-los como os direitos considerados básicos para qualquer ser humano, independentemente de condições pessoais específicas. Como os direitos fundamentais sistematizam as noções mais básicas e centrais que regulam a vida social, política e jurídica brasileira, salientamos sua íntima e indissolúvel vinculação com a própria noção de "Constituição" e de "Estado de Direito". São simultaneamente base e fundamento do Estado de Direito. E o exercício do poder estatal está condicionado [ao menos em tese] aos limites fixados na sua Constituição (Sarlet, 2010).

Apesar de as dimensões dos direitos fundamentais não serem objeto deste artigo, para uma adequada compreensão da sua importância propomos uma breve digressão sobre essa temática. Os direitos fundamentais de primeira dimensão afirmam-se como direitos do indivíduo ante o Estado, demarcando uma zona de não intervenção estatal na autonomia individual. Cuida-se dos direitos civis e políticos, que correspondem à fase inicial do constitucionalismo ocidental. A esfera dos direitos de segunda dimensão englobam as chamadas "liberdades so- 
ciais", entre elas a liberdade de sindicalização, o direito de greve, bem como o reconhecimento de direitos dos trabalhadores (Sarlet, 2010). Já os direitos fundamentais de terceira dimensão [e entre eles o ambiente ecologicamente equilibrado] caracterizam-se pela titularidade coletiva ou difusa. Dentre eles, a paz, a autodeterminação dos povos, o ambiente e qualidade de vida, bem como o direito à conservação e utilização do patrimônio histórico e cultural (Sarlet, 2010).

Entre as funções atribuídas aos direitos fundamentais está o dever de proteção [Schutzpflichten] do Estado, no sentido de que a esse incumbe zelar, inclusive preventivamente, pela sua proteção (Sarlet 2010). Logo, mediante uma interpretação absolutamente linear da Constituição podemos concluir que a tutela do direito ao ambiente ecologicamente equilibrado consiste em um dever geral atribuído principalmente ao Estado. Dever esse que desemboca na obrigação de proteger de forma efetiva o ambiente. Ou, segundo a interpretação de Silva (2004), no dever geral do Poder Público e da coletividade de não degradá-lo.

No âmbito da doutrina germânica que influenciou diretamente o direito ambiental brasileiro, o Princípio de Precaução [Vorsorgeprinzip] tem como essência a ideia de que a sociedade pode evitar danos ambientais mediante planejamentos cautelosos que freiem o desenvolvimento de atividades que produzem, ou que possam vir a produzir, alguma espécie de dano ao ambiente (Machado, 2004). Nesse sentido coube às diferentes legislações mundiais um olhar mais sensível à saúde das pessoas [enxergados coletivamente], às futuras gerações, à manutenção das funções ecológicas, aos efeitos negativos em longo prazo da exploração predatória dos "recursos" naturais, bem como aos benefícios tangíveis e intangíveis do seu uso-limitado [e até não uso] (Canotilho; Leite, 2012). Em que pese o cunho antropocêntrico do direito ambiental brasileiro, o reconhecimento do direito a um meio ambiente ecologicamente equilibrado como um direito fundamental configura-se como "uma extensão do direito à vida, quer sob o enfoque da própria existência física e saúde dos seres humanos, quer quanto ao aspecto da dignidade dessa existência - a qualidade de vida -, que faz com que valha a pena viver" (Milaré, 2005, p.762). Nesse contexto, o direito ambiental brasileiro surge como ramo autônomo do Direito, possuir princípios próprios que norteiam a tutela dos bens ambientais, entre eles o supracitado Princípio de Precaução. Em realidade, segundo Silva (2004), o princípio de precaução emerge do disposto no artigo 225 do texto constitucional de 1988 , impondo aos operadores do direito a busca de respostas ao imperativo de segurança reforçada e a regulamentação das dúvidas nascidas da ciência, para que se possa garantir o direito ao meio ambiente ecologicamente equilibrado, tanto às presentes quanto às futuras gerações (Brasil, 1988). Podemos afirmar com certa tranquilidade que, no plano teórico-jurídico, esse Princípio, que tem sua origem no direito germânico, hoje corresponde à própria essência do direito ambiental brasileiro e, por essa razão, é um dos mais importantes instrumentos jurídicos que visa a tutela ambiental, como veremos a seguir (Silva, 2004). 
O artigo, além desta introdução, está dividido em três itens. No primeiro deles, sugerimos um panorama geral inserção do princípio de precaução no direito ambiental brasileiro a partir das convenções internacionais. O segundo item refere-se à incorporação do princípio de precaução pela a doutrina jurídica brasileira. Esclarecemos que esse segundo item não alcançará nem todos os doutrinadores brasileiros, nem toda a abrangência que o tema merece, tratando-se, tão somente, de apresentar uma visão geral sobre o tema. No terceiro item, abordamos a [in] eficácia do princípio de precaução na realidade brasileira, citando alguns exemplos. Por fim, apresentamos nas considerações finais a necessidade de postura precautória em face dos constantes descumprimentos aos direitos fundamentais.

\section{A inserção do Princípio de Precaução no direito ambiental}

No início da década de 1980, o princípio de precaução foi inscrito na maior parte dos atos internacionais bilaterais e multilaterais que dizem respeito à proteção ambiental (Sadeleer, 2004). Entre nós merece destaque duas convenções internacionais assinadas, ratificadas e promulgadas pelo Brasil que, segundo Machado (2004), inserem o princípio de precaução no plano nacional: a Convenção da Diversidade Biológica e a Convenção-Quadro das Nações Unidas sobre a Mudança do Clima. De acordo com a Convenção da Diversidade Biológica, quando existir ameaça de sensível redução ou perda de diversidade biológica, a falta de plena certeza científica não deve ser usada como razão para postergar medidas para evitar ou minimizar essa ameaça. Já o artigo terceiro da Convenção-Quadro das Nações Unidas sobre a Mudança do Clima estabelece que medidas de precaução para prever, evitar ou minimizar as causas e efeitos das mudanças climáticas devem ser adotadas pelas Partes. E, quando surgirem ameaças de danos sérios ou irreversíveis, a falta de plena certeza científica não deve ser usada como razão para postergar essas medidas. Em suma, enquanto para a Convenção da Diversidade Biológica basta haver ameaça de sensível redução de diversidade biológica para que o princípio de precaução seja implantado, para Convenção de Mudança do Clima há a exigência que a ameaça seja de dano sério ou irreversível.

Sobre a diferença nas redações das convenções supracitadas, Machado (2002) explica que ambas estabelecem os objetivos de se evitar ou minimizar os danos ambientais. E acrescenta que as duas Convenções são aplicáveis quando houver incerteza científica diante da ameaça de redução ou de perda da diversidade biológica ou ameaça de danos causadores de mudança do clima (Machado, 2002; 2004; Attanasio Júnior; Attanasio, 2004). Vale ainda mencionar que no dia 29 de janeiro de 2000, a Conferência das Partes da Convenção sobre Diversidade Biológica (CDB) adotou seu primeiro acordo suplementar, conhecido por Protocolo de Cartagena sobre Biossegurança. Esse Protocolo tem por objetivo garantir o manuseio, transporte e uso de organismos vivos modificados resultantes da biotecnologia moderna que possam ter efeitos adversos sobre a 
diversidade biológica, tendo igualmente em conta riscos para a saúde humana. De acordo com o Ministério do Meio Ambiente brasileiro, a adoção do Protocolo pelos Países-Partes da Convenção constitui-se em um importante marco normativo internacional que aponta as necessidades de proteção ambiental e à saúde humana e, também, da promoção do comércio internacional. Não cabe aqui a análise do mérito da viabilidade de convivência harmônica entre as necessidades apontadas pelo Protocolo: proteção ambiental e à saúde humana versus promoção do comércio internacional. De qualquer modo, registra-se apenas que é um tema bastante controverso, que mobiliza opiniões e valores bastante arraigados (Reichardt et al., 2016).

Em que pesem as críticas apontadas, pode-se dizer que Protocolo visa, ao menos formalmente, um equilíbrio entre a proteção da biodiversidade e a defesa do fluxo comercial dos organismos geneticamente modificados. É considerado pelo Ministério do Meio Ambiente (MMA) brasileiro como um instrumento essencial para a regulação do comércio internacional seguro de produtos transgênicos. Para tanto, o Protocolo criou uma instância internacional para discutir os procedimentos que devem nortear a introdução de organismos vivos modificados nos territórios dos respectivos Países-Partes. Estabelece, também, um procedimento para um acordo de aviso prévio para assegurar que os países tenham as informações necessárias para tomar decisões conscientes antes de aceitarem a importação de organismos geneticamente modificados para seu território. Nesse sentido, entende-se que o Protocolo de Cartagena sobre Biossegurança incorpora o Princípio de Precaução, considerando-o como um dos pilares desse instrumento, devendo nortear as ações políticas e administrativas dos governos. Ainda de acordo com o MMA, esse instrumento internacional tem por objetivo proteger os direitos humanos fundamentais como a saúde humana, a biodiversidade e o equilíbrio ecológico do meio ambiente, sem os quais ficam prejudicados os direitos à dignidade, à qualidade de vida e à própria vida. Cuidam-se dos direitos fundamentais expostos na fase introdutória ou, se preferirmos, dos direitos consagrados pela Declaração Universal dos Direitos Humanos da Organização das Nações Unidas, de 1948.

\section{Como a doutrina jurídica incorpora o Princípio de Precaução?}

A noção de "precaução" tem origem entre os gregos e significa "ter cuidado" e "estar ciente" (Myhr; Traavik, 2003). Na década de 1970, como resposta à poluição industrial, o conceito é resgatado pelo direito germânico de onde emerge o Princípio de Precaução. Vinte anos depois, o Princípio de Precaução estava estabelecido em praticamente todos os países da Europa Ocidental e foi estendido aos diferentes setores da economia (Machado, 2004). O Princípio de Precaução funciona como uma espécie de in dubio pro ambiente: na dúvida decide-se a favor do ambiente. Acima de tudo, impõe que a responsabilidade de produzir os resultados científicos que provêm a inocuidade ou a insignificância dos riscos seja atribuída a quem tem interesse no desenvolvimento da atividade 
(Canotilho; Leite, 2012). Silva (2004) vai além, entende que o princípio de precaução afirma a necessidade de uma nova postura, em face dos riscos e incertezas científicas. Nessa mesma linha, Nodari e Guerra (2003) apontam que a precaução relaciona-se com a associação respeitosa e funcional do homem com a natureza. Tratam a precaução como ações antecipatórias para proteger a saúde das pessoas e dos ecossistemas. Segundo esses autores, precaução é, portanto, um dos princípios que guia as atividades humanas e incorporam parte de outros conceitos como justiça, equidade, respeito, senso comum e prevenção (Nodari; Guerra, 2003).

Apesar das várias formulações existentes sobre o princípio de precaução pela doutrina brasileira, segundo Machado (2004) é possível destacar dele algumas características comuns. Entre elas destaca-se a incerteza/certeza do dano ambiental. Isto é, o Princípio de Precaução é aplicável quando ainda existe a incerteza. Em outras palavras, não se deve aguardar que o dano se torne certo (Machado, 2004). Outra característica apresentada pelo autor (Machado, 2004) versa sobre sua relação com os princípios constitucionais da Administração Pública brasileira. O Princípio de Precaução entra no domínio do direito público através do "poder de polícia" conferido à Administração. Em nome desse Princípio, o Estado pode/deve suspender uma grande liberdade, ainda mesmo que ele não possa apoiar sua decisão em uma certeza científica (Machado, 2004).

Em relação à inversão do ônus da prova no que se refere à precaução, adverte-se que, no Brasil, em razão da Lei de Política Nacional do Meio Ambiente, a responsabilidade civil objetiva $\left(\operatorname{art} .14, \mathfrak{S} 1^{\circ}\right)$. Isto é, independe da aferição de culpa, ou de gradação de envolvimento do agente causador do dano. Podemos dizer, portanto, que a inversão do ônus da prova impõe ao empreendedor o encargo de provar que a atividade a ser implantada não é efetiva ou potencialmente degradadora. Vale, ainda, ressaltar a incriminação da ausência de precaução. De acordo com art. 54 da Lei n.9.605, de 12.2.1998, "Causar poluição de qualquer natureza em níveis tais que resultem ou possam resultar em danos à saúde humana, ou que provoquem a mortandade de animais ou a destruição significativa da flora: Pena - reclusão, de um a quatro anos, e multa". E, em seu parágrafo terceiro, estabelece que: "Incorre nas mesmas penas previstas no parágrafo anterior quem deixar de adotar, quando assim o exigir a autoridade competente, medidas de precaução em caso de risco de dano ambiental grave ou irreversível".

Pelo exposto, podemos concluir que para a doutrina brasileira apresentada neste artigo, princípio de precaução aflora do artigo 225 do texto constitucional de 1988 e, embora não diretamente expresso, é considerado como princípio geral do direito ambiental que define uma nova dimensão da gestão do ambiente e da minimização dos riscos (Silva, 2004). Em consonância com os diferentes autores citados, Silva (2004) esclarece que constitui flagrante descumprimento ao mandamento constitucional o não respeito a esse princípio, isto é, "o não afastamento do perigo que um conjunto de atividades possa vir a causar, tanto 
para as gerações presentes quanto para as gerações futuras, comprometendo o direito de todos ao meio ambiente ecologicamente equilibrado" (Silva, 2004, p.78-9).

\section{O Princípio de Precaução e sua eficácia na realidade nacional}

Neste último item, tecemos algumas considerações que não esgotam o tema do princípio de precaução no Brasil, tampouco sua [in] eficácia na realidade brasileira. Em estudos jurídicos, uma análise sobre a mesma norma [latu sensu] pode ser feita em ao menos três planos [não estanques]: existência, validade e eficácia. No primeiro deles questiona-se: essa norma existe? Se positiva a resposta à pergunta que se sucede refere-se à sua validade [da norma existente] no ordenamento, seja ele nacional, seja internacional. Na terceira etapa questiona-se se essa norma [que existe e é válida] surte efeitos no plano real. Em que pesem os posicionamentos doutrinários que validam, com muita propriedade, o princípio de precaução no ordenamento brasileiro, sua eficácia na realidade nacional é muitas vezes questionável. Citaremos, a título de exemplo, dois aspectos bastante emblemáticos de sugerem sua violação e, em seguida, um exemplo de sua aplicação.

O primeiro deles se refere à legalização dos organismos geneticamente modificados [OGM] no Brasil. Apesar de ser signatário dos tratados mencionados e a despeito das diversas incertezas científicas sobre essa tecnologia, o Brasil promoveu a ampla difusão de plantas geneticamente modificadas [GM] nas suas paisagens. A legalização da soja GM se deu no ano 2003, por meio de medidas em caráter de urgência: o então presidente da República através da Medida Provisória (MP) 113/2003 autorizou a comercialização da soja Geneticamente Modificada (GM) da safra de 2003 (Brasil, 2003). Isso se deu no mesmo ano em que, de um lado, o Poder Legislativo discutia a lei de biossegurança dos Organismos Geneticamente Modificados (OGM) e, de outro, o Poder Judiciário condicionava a comercialização da soja transgênica à prévia realização do estudo de impacto ambiental. Antes mesmo da entrada em vigor da Lei de Biossegurança, a comercialização da safra de 2003 foi autorizada pela medida provisória acima mencionada sem o prévio estudo de impacto ambiental. A autorização para a comercialização foi restrita à soja da safra de 2003 e criou-se a obrigação da destruição do estoque mediante incineração após 31 de dezembro de 2004 (MP 113/2003, art. $\left.1^{\circ} \$ 1^{\circ}\right)$. Contudo, em ato contínuo, autorizou-se também a comercialização da soja transgênica das safras de 2004 e 2005 (Ayala, 2011; Reichardt, 2015; Reichardt et al., 2016). No ano 2009, o Brasil havia assumido o posto de segundo país em área plantada com culturas GM (aproximadamente 21 milhões de hectares) (International Service for the Acquisition of Agri-Biotech Applications - ISAAA, 2010). No ano seguinte (2010), foi apontado como maior consumidor de agrotóxicos do mundo (consumo aproximado de 800 milhões de litros). No início de 2016, o Brasil possui liberado comercialmente 42 variedades de plantas GM de cinco espécies distintas (soja, algodão, milho, 
feijão e eucalipto) (Brasil, 2016). O primeiro levantamento da adoção de biotecnologia agrícola no Brasil para a safra 2015/2016 realizado pela Céleres indica que a área total com culturas transgênicas (soja, milho e algodão) alcançará 44,2 milhões de hectares, o que corresponde a $90,7 \%$ da área cultivada com essas três culturas. Pode-se, portanto, concluir que, nesse caso, o princípio de precaução não foi aplicado, ou que foi apenas formalmente observado (Reichardt, 2015; Reichardt et al., 2016).

O segundo exemplo refere-se às propostas do já citado Projeto de Lei (PL) n.3.729/04, que tem por objetivo "definir parâmetros gerais" que devem ser cumpridos por empreendedores no caso de obras com risco ambiental, reduzindo ou dispensando instrumentos jurídicos de governança socioambiental consagrados no nosso ordenamento jurídico, como o estudo prévio de impacto ambiental e as audiências públicas. De acordo com a análise técnica ${ }^{2}$ redigida por Ivan Carneiro Castanheiro, haverá grandes riscos ao ambiente, relegando-se os princípios de precaução e prevenção internacionalmente vigentes em Direito Ambiental à mera disposição formal constantes de tratados internacionais de que o Brasil é signatário, cuja degradação ambiental decorrente dessas aprovações poderá ser irreversível ou de difícil reparação ao longo dos anos.

Por outro lado, um exemplo de aplicação recente do princípio de precaução e prevenção (desproporcional, a nosso ver) refere-se à proibição de comercialização de produtos de origem animal produzidos pela agricultura familiar, como leite e derivados, ovos, mel, frango caipira e carnes pela vigilância sanitária, nos municípios de Água Boa, Canarana e Querência, todos do estado do Mato Grosso. Segundo os órgãos sanitários municipais, o princípio de precaução é invocado para proteger o consumidor e a saúde da população, tendo em vista o risco que esses alimentos podem oferecer se manipulados fora das técnicas e padrões básicos de higiene. Em trabalho de campo na região do Alto Xingu, no âmbito do Projeto Temático "XINGU Project: Integrating land use planning and water governance in Amazonia: towards improved fresh water security in the agricultural frontier of Mato Grosso", vinculado ao Centro de Energia Nuclear na Agricultura da Universidade de São Paulo, visitamos alguns assentamentos rurais das municipalidades supracitadas. Por meio de diferentes entrevistas e observação de campo, identificamos que a atividade econômica que predomina nos assentamentos é o cultivo de soja através de uma parceria agrícola. Muitos agricultores alegam que não thes resta outra opção de cultivo. A produção de leite e os produtos derivados do leite estão em declínio e alguma agricultura de subsistência pode ainda ser encontrada. A assistência técnica prestada aos assentamentos não é suficiente para superar os graves problemas de cultivo enfrentados pelos pequenos produtores, afetando negativamente a tradição e a história do agricultor familiar. Por outro lado, a decisão da vigilância sanitária foi tomada sem qualquer apoio ou incentivo técnico/financeiros aos pequenos produtores. Vale ainda citar que todos os pequenos agricultores entrevistados no 
trabalho de campo supracitado reclamaram do aumento do uso de pesticidas na região. Relatam, entre outros sintomas de contaminação por agrotóxicos, dores de cabeça, urticária e aumento dos casos de cânceres e abortamentos na região. Como é sabido, o Mato Grosso é o estado de maior produção de soja do Brasil e, pela extensão das lavouras, muitas das pulverizações são feitas por via aérea. Ora, se o bem jurídico tutelado pela administração local é a saúde humana, por qual razão o princípio de precaução alcança o mercado informal de produtos coloniais da Feira do Pequeno Produtor e é desconsiderado no que concerne aos agrotóxicos?

Contudo, nessa mesma região, a situação do povo xavante nos parece ainda mais grave diante dos impactos da expansão da soja no Alto Xingu. Segundo relatório do Unicef, amplamente divulgado em setembro de 2014, um dos problemas mais graves enfrentados pelo Brasil é a elevada taxa de mortalidade infantil das populações indígenas. Os xavantes apresentam a segunda mais elevada taxa de mortalidade do Brasil, superando os índices de países como Quênia, Gana, Namíbia e Zimbabwe. A desnutrição está entre as principais causas de mortalidade infantil (Vieira, 2015). Em relação à população xavante adulta, mais de $65 \%$ dos indígenas pesquisados desenvolveram síndrome metabólica - condição na qual os fatores de risco para doenças cardiovasculares e diabete mellitus ocorrem em um mesmo indivíduo. Entre as mulheres a incidência da síndrome metabólica é ainda mais elevada, atingindo 76,2\% das indígenas que participaram do estudo e desenvolveram a doença (Soares et al., 2015). E aqui adaptamos a indagação feita acima, se o bem jurídico tutelado pela administração local é a saúde humana, por qual razão o princípio de precaução não tem qualquer eficácia em relação ao povo xavante?

O cerne do nosso questionamento a partir dos exemplos acima versa sobre as possibilidades de se estabelecer um possível critério universal de "necessidade" e/ou "qualidade de vida", conforme sugerido pela doutrina. Por quem serão estabelecidos esses parâmetros? Para quem? Obedecerão a que critérios? A que valores? Ainda questiona-se o que é uma "melhoria" para cada um desses diferentes povos. Melhor para quem? Positivas ou negativas para quem? Previsíveis ou imprevisíveis por quem? Quem traduzirá o seu grau de importância? Como escolher os parceiros e tópicos para a tradução intercultural? Como formar decisões partilhadas e distingui-las das impostas?

Por fim, problematizamos a noção de "desenvolvimento" - e de seus derivados como ecodesenvolvimento, desenvolvimento sustentável trazida pela doutrina no segundo item. A expressão "desenvolvido", com todos os derivados que aparecem ligados ao termo, como "sub"; "semi"; "pós", traz consigo uma ideia evolutiva linear de "caminho a ser percorrido": do pior para o melhor, do simples para o complexo, do pouco para o muito, do inferior para o superior (Radomsky, 2011; Machado, 2005). De acordo com Escobar (2012), longe de ser um conceito utilizado pela economia para qualificar um estágio transitório em que se en- 
contra uma determinada nação, o discurso do desenvolvimento funciona como um mecanismo de hierarquização e dominação cultural. Isso porque a trajetória semântica do conceito de desenvolvimento vem incrustada de uma carga ideológica que condiciona a forma de se ler, pensar e representar o mundo. E conclui que o desenvolvimento não é apenas um problema na medida em que o projeto desenvolvimentista falha, mas também quando suas metas são alcançadas.

A análise feita por Escobar (2012) é perfeitamente extensível ao contexto agrícola brasileiro, ao menos no que se refere às fronteiras agrícolas amazônicas, em especial o Alto Xingu. Nessa região de grande produção de soja, desenvolver significa transformar a diversidade das paisagens em campos uniformes de gado e lavoura, transportando para os biomas tropicais brasileiros o mesmo modelo de agricultura europeia e norte-americana. Em consequência, a região é palco de diferentes impactos ambientais, entre eles: assoreamento de rios e reservatórios; levantamento dos níveis do lençol freático; alteração da composição do solo; contaminação por agrotóxicos em águas, alimentos, animais e humanos; danos à vegetação riparia ou vegetação nativa em áreas contínuas extensas; aparecimento de novas pragas ou aumento/resistência das já conhecidas; perda de hábitat natural de diversas espécies vegetais e animais; alterações no clima local. E esse modelo de desenvolvimento tampouco tem promovido a afirmação de direitos fundamentais das populações locais. Pelo contrário, a população enfrenta diferentes formas de violação de direitos humanos e socioambientais. Nesse sentido, considerar que o ambiente constitui simultaneamente condição de existência, recursos materiais, econômicos e culturais dos povos, talvez seja um primeiro passo relevante no estabelecimento de um critério mais condizente com a justiça socioambiental.

\section{Considerações finais}

O Princípio de Precaução aflora do artigo 225 do texto constitucional de 1988 e, embora não diretamente expresso, é considerado como princípio geral do direito ambiental que define uma nova dimensão da gestão do ambiente e da minimização dos riscos. Entretanto, os exemplos citados neste artigo sugerem que o princípio de precaução não foi aplicado, ou que foi apenas formalmente observado, no plano nacional. Não se pretende, sob nenhuma hipótese, olvidar sua importância ímpar no ordenamento nacional mediante críticas apontadas neste artigo. Muito pelo contrário! Uma postura precautória torna-se ainda mais urgente diante do tempo transcorrido, da iminência de um risco/perigo/danos irreversível e dos constantes descumprimentos aos direitos fundamentais.

\section{Notas}

1 Constituição Federal Brasileira, artigo 225, caput: "Todos têm direito ao meio ambiente ecologicamente equilibrado, bem de uso comum do povo e essencial à sadia qualidade de vida, impondo-se ao poder público e à coletividade o dever de defendê-lo e preservá-lo para as presentes e futuras gerações” (Brasil, 1988). 
2 Nota Pública do Movimento do Ministério Público Democrático contra Projeto de Lei que pode causar mais tragédias ambientais no Brasil e no mundo. Disponível em: <https://mpd.org.br/13122016-nota-publica-do-mpd-movimento-do-ministerio-publico-democratico-contra-projeto-de-lei-que-pode-causar-mais-tragedias-ambientais-no-brasil-e-no-mundo/>. Acesso em: 6 abr. 2017.

\section{Referências}

ATTANASIO JÚNiOR, M. R.; ATtANASIO, G. M. C. Análise do Princípio da Precaução e suas Implicações no Estudo de Impacto Ambiental. In: II Encontro da ANPPAS, 26 a 29 de maio de 2004. Indaiatuba, São Paulo. 2004. Disponível em: <http://www.anppas.org.br/encontro_anual/encontro2/GT/GT09/grabriela.pdf>. Acesso em: 26 ago. 2016.

AYALA, P. A. Processo ambiental e o direito fundamental ao meio ambiente. Rio de Janeiro: Lumen Juris, 2011. 46lp.

AYALA, P. A.; LEITE J. R. M. Direito ambiental na sociedade de risco. Rio de Janeiro: Forense Universitária, 2002.

BRASIL. Constituição da República Federativa do Brasil. Brasília: Senado, 1988.

BRASIL. Medida Provisória 113/2003. Estabelece normas para a comercialização da produção de soja da safra de 2003 e dá outras providências. 2003.

BRASIL. Ministério da Ciência, Tecnologia e Inovação. Comissão Técnica Nacional de Biossegurança. Relatório Anual 2016. 2016.

CANOTIlHO, J. J. G.; LEITE, J. R. M. (Org.) Direito Constitucional Ambiental Brasileiro. 5.ed. Rio de Janeiro: Saraiva, 2012.

ESCOBAR, A. Encountering Development: The making and unmaking of the third world. Princeton: Princeton University Press, 2012.

MACHADO, P. A. L. Direito Ambiental Brasileiro. 10.ed. São Paulo: Malheiros Editores, 2002.

Princípio da precaução no direito brasileiro e no direito internacional e comparado. In: VARELlA, M. D.; PLATIAU, A. F. B. (Org.) Princípio da Precaução. Belo Horizonte: Del Rey, 2004. p.551-72.

MACHADO. V. F. A produção do discurso do desenvolvimento sustentável de Estocolmo à Rio-92. Brasília, 2005. Tese (Doutorado) - Centro de Desenvolvimento Sustentável, Universidade de Brasília. Brasília, 2005. Disponível em: <http://www.anppas.org.br/ encontro_anual/encontro3/arquivos/TA398-07032006-233539.DOC>. Acesso em: 26 out. 2017.

MILARÉ, E; MACHADO, P. A. L. (Org.) Doutrinas essenciais: Direito Ambiental. São Paulo: Revista dos Tribunais, 2011. v.I.

MORAES, A. de. Direito Constitucional. São Paulo: Atlas, 2010.

MYHR, A. I.; TRAAVIK, T. Genetically modified (GM) crops: precautionary science and conflicts of interests. Journal of Agricultural and Environmental Ethics, v.16, p.227-47, 2003. 
NODARI, R. O.; GUERRA, M. P. Plantas transgênicas e seus produtos: impactos, riscos e segurança alimentar. Revista de Nutrição, v.16, n.1, p.105-16, 2003.

RADOMSKY, G. F. W. Desenvolvimento, pós-estruturalismo e pós-desenvolvimento: a crítica da modernidade e emergência de "modernidades" alternativas. Revista Brasileira de Ciências Sociais, São Paulo, v.26, p.149-62, 2011.

REICHARDT, F. V. Função socioambiental: As patentes de plantas geneticamente modificadas no Brasil. Düsseldorf: Editora Saarbrücken: Novas Edições Acadêmicas, 2015.

REICHARDT, F. V.; GARAVELLO, M. E. G.; MOLINA, S. M. G.; BALLESTER, M. V. R. Biotecnologia moderna, direito e o pensamento abissal. Revista de Direito Internacional, v.13 p.295-314, 2016.

SADELEER, N. O estatuto do princípio da precaução no direito internacional. In: VARELla, M. D.; PlatiaU, A. F. B. (Org.) Princípio da Precaução. Belo Horizonte: Del Rey, 2004. p.47-74.

SARLET, I.W. A eficácia dos direitos fundamentais: Uma teoria geral dos direitos fundamentais na perspectiva constitucional. 10.ed. Porto Alegre: Livraria do Advogado, 2010.

SILVA, S. T. Princípio da precaução: uma nova postura em face dos riscos e incertezas científicas. In: VARELlA, M. D.; PlatiAU, A. F. B. (Org.) Princípio da Precaução. Belo Horizonte: Del Rey, 2004. p.75-92.

SOARES L. P. et al. Prevalence of metabolic syndrome in the brazilian Xavante indigenous population. Diabetology \& Metabolic Syndrome, v.7, p.105-12, 2015.

VIEIRA M. C. Pequenos e invisíveis: A mortalidade de crianças indígenas. Revista Cerscer, São Paulo, 2015. Disponível em: <http://premio.vladimirherzog.org/uploads/ pequenos-e-invisiveis-a-mortalidade-das-criancas-indigenas.pdf $>$. Acesso em: $5 \mathrm{dez}$. 2016.

RESUMO - Este artigo tem por objetivo revisar o Princípio de Precaução no ordenamento nacional ante os acordos internacionais assumidos pelo Brasil. Optamos por uma abordagem constitucional na fase introdutória, pois Princípio de Precaução, que emerge do artigo 225 da Constituição Federal, é considerado como Princípio Geral do Direito Ambiental. O artigo está dividido em três itens. No primeiro deles, como introdução, sugerimos um panorama da sua inserção no direito ambiental brasileiro a partir das convenções internacionais. O segundo item refere-se à sua incorporação pela a doutrina jurídica brasileira. No terceiro, apresentamos alguns exemplos da sua [in] eficácia no contexto nacional. As considerações finais evocam a urgência de uma postura precautória.

PALAVRAS-ChaVE: Princípio de Precaução, Direito ambiental, Ambiente ecologicamente equilibrado, Direito fundamental, Convenções internacionais.

ABSTRACT - The purpose of this article is to review the Precautionary Principle in Brazilian law in relation to the international agreements assumed by the country. We opted for a constitutional approach in the introductory phase, since the Precautionary Principle, which emerges from Article 225 of the Brazilian Federal Constitution, is considered as a general principle of national environmental law. The article is divided into three items. In the first one, introduction, we suggest an overview of the Precautionary 
Principle into the Brazilian environmental law through the international conventions. The second item refers to the incorporation of this principle by the Brazilian legal doctrine. In the third item, we present some examples of the Precautionary Principle ineffectiveness in the Brazilian context. The final considerations evoke the urgency of a precautionary approach.

KEYWORDS: Precautionary Principle, Environmental law, Ecologically balanced environment, Fundamental law, International conventions.

Fernanda Viegas Reichardt é graduada em Direito pela Universidade Presbiteriana Mackenzie, doutora em Ciências pelo Programa Interunidades em Ecologia Aplicada, pós-doutora pelo Centro de Energia Nuclear na Agricultura ambos pela USP; Pósdoutoranda do Centro de Pesquisa MARE da Fundação Portuguesa para Ciência e Tecnologia e Pesquisadora Colaboradora do Instituto de Estudos Avançados da USP (2018). @-fv.reichardt@gmail.com / https://orcid.org/0000-0003-0351-1052.

Mayara Regina Araújo dos Santos é graduanda em Ciências Biológicas e em Licenciatura em Ciências Biológicas pela Escola Superior de Agricultura "Luiz de Queiroz" da Universidade de São Paulo (ESALQ-USP). @ - mayara.araujo.santos@usp.br https://orcid.org/0000-0002-4091-5411

Recebido em 31.1.2018 e aceito em 16.7.2018.

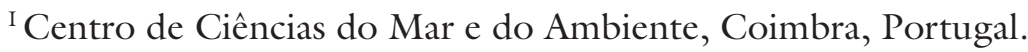

II Escola Superior de Agricultura "Luiz de Queiroz”, Universidade de São Paulo, Piracicaba, São Paulo, Brasil. 